\title{
Clinical Profile of Children with Intellectual Developmental Disorder Institution Based Cross Sectional Study
}

\author{
Varsha vidyadharan $^{1 *}$, Teena Mary Joy ${ }^{2}$, P.S. Sukumaran ${ }^{3}$
}

\section{ABSTRACT}

Background : Intellectual Developmental Disorder (IDD) has overall prevalence of 1-3\% in the global scenario. It also produces psychological, social and financial distress to the whole family and society, and the chance of co-morbid psychiatric disorders are high. This study aimed to assess the socio demographic profile of children with IDD, clinical profile, social maturity quotient, extent of medical and psychiatric co morbidities like neuromotor impairment, autism spectrum disorders, attention deficit hyperactivity disorder, and to compare these children based on age and sex to see whether there is any difference in manifestations between child and adolescent group and to understand burden of behavioural problems in these children. Materials and methods: By descriptive research methodology, sample of 100 children with intellectual disability attending a special school in Calicut, Kerala evaluated using a specially designed proforma, written informant consent, questionnaire to be filled by parents, INCLEN diagnostic tool for neuro motor impairment, INCLEN diagnostic tool for autism spectrum disorders, INCLEN diagnostic tool for ADHD, AAMD adaptive behavioural scale revised, VINELANDS social maturity scale. Data analysed with appropriate statistical tests and results obtained were interpreted accordingly. Results: Prevalence of IDD was more in males. Mean social quotient observed was 48.79+_16.79.Developmental delay in all spheres of development was reported in 96 percent of sample population. Family history of IDD was reported in 20 percent of sample. Most common medical co morbidity noted was seizure disorder. Psychiatric co morbidities were less reported in children with Down syndrome. Increased chance of neuromotor impairment was found in children with family history of IDD. Children with comorbid medical disorders were found to have increased chance of neuromotor impairment. Pervasive developmental disorders and ADHD was reported. Odd behaviour was the most common behavioural problem reported.

\footnotetext{
${ }^{1}$ Assistant Professor, Department of Psychiatry, Govt Medical College, Calicut, Kerala University of Health science, Kerala, India

${ }^{2}$ Assistant Professor, Department of Community Medicine, Amrita Institute of Medical Sciences, Kochi, Amrita Vishwa Vidyapeetam, Kerala, India

${ }^{3}$ Professor in Special Education, School of Behavioural Sciences, Mahatma Gandhi University, Kottayam, Kerala, India

*Responding Author

(C) 2016 Vidyadharan V, Joy T, Sukumaran P; licensee IJIP. This is an Open Access Research distributed under the terms of the Creative Commons Attribution License (http://creativecommons.org/licenses/by/2.0), which permits unrestricted use, distribution, and reproduction in any Medium, provided the original work is properly cited.
} 


\section{Clinical Profile of Children with Intellectual Developmental Disorder Institution Based Cross Sectional Study}

Conclusions: Detailed study of clinical profile of children with IDD has implications in early identification, intervention, management and prevention of same.

Keywords: Mental Retardation, Intellectual Developmental Disorder, Clinical Profile, Co Morbidity.

Mental retardation (MR)] according to the World Health Organization has overall prevalence of $1-3 \%$ in the global scenario ${ }^{1}$. MR produces psychological, social and financial distress to the whole family, particularly parents, as they are usually the only constant caretakers. In Diagnostic and statistical Manual of Mental disorder (DSM 5), the diagnosis of mental retardation is revised from DSM IV, now called as intellectual disability or developmental disorder(IDD) ${ }^{2}$. This significant change addresses its impact on a person's functioning and criteria improvements to encourage more comprehensive patient assessment. Intellectual disability involves impairments of general mental abilities that impact adaptive functioning in three domains conceptual, social and practical. From Indian side it is generally considered that $2 \%$ of the Indian population constitutes persons with mental retardation and its prevalence varies from 0.22 to $32.7 \%$ per thousand populations ${ }^{3,4}$.

The term clinical is usually used in relation to or based on work done with real patients, where as clinical profile denotes valid and reliable clinical interviews done by investigators on an area of medical research. IDD is considered chronic and often co-occurs with other mental conditions like depression, attention-deficit/hyperactivity disorder, and autism spectrum disorder. They can develop any neuropsychiatric disorder present in persons of normal intellect. The frequency and type of psychiatric or behavioural disorders varies according to the severity of intellectual disability, as well as a variety of other condition, including medical problems, environmental changes and circumstances ${ }^{5,6}$. Epidemiological studies of psychiatric disorders in individuals with intellectual disabilities revealed higher rates of psychiatric disorders in children with versus those without intellectual disability, and higher rates in children and adult with more severe forms of intellectual disability versus those with milder forms ${ }^{7}$. Other studies have shown that the developmental course of psychopathology is similar from ages 6 to 18 years for children with and without intellectual disabilities ${ }^{8}$.

Intellectual disability has a varied phenomenology in different parts of world and often the diagnosis and treatment of neuropsychiatric disorders in individual with intellectual developmental disorder has been a neglected aspect. There are limited published studies on clinical profile of children with intellectual disabilities. Again institution based studies where severely retarded children are seen is relatively less. Considering all above aspects this study aimed to study the clinical profile of children with intellectual developmental disorder and to

study co morbid neuropsychiatric disorders in these children and compare these children with 


\section{Clinical Profile of Children with Intellectual Developmental Disorder Institution Based Cross Sectional Study}

respect to age and other parameters. We also aimed to understand the burden of behavioural problems and social maturity level of these children.

\section{METHODS}

This is an institution based cross sectional study of children and adolescents with IDD, conducted during a period of 9 months from April 2015-December 2015. Data was collected after institutional research committee approval of the institute where the principal investigator is working at present. Children between the ages of 6-18 years studying in special schools were recruited for the study. Children with intellectual developmental disorder were randomly selected with a sample size of 100 (4pq/d2; considering p as 53\% and fixing d -20 the sample size is 58 . Data were collected from 100 children in a special school. Study was conducted in an institution where these children were studying for training and education after diagnosis of IDD from clinical experts and psychological assessment in various treatment centres in Calicut district. Children and adolescents attending these school were assessed clinically and diagnosis was confirmed by investigator considering DSM-5 criteria for intellectual developmental disorders (who is a psychiatrist working in the field of child and adolescent psychiatry) and thus were included in the study. The children who satisfied the inclusion and exclusion criteria listed below were included in the study.

\section{Inclusion Criteria}

1. Diagnosis of Intellectual Developmental Disorder as per Diagnostic and Statistical Manual of Mental Disorders -5 (DSM-5)

2. Chronological age between 6-18 years

3. Both sexes

4. Availability of at least one parent/teacher/primary care-giver who has been in close contact with the child in the past 6 months.

5. Willingness to participate documented through written informed consent.

\section{Exclusion Criteria}

Children from who informed consent could not be obtained.

\section{Tools:}

1. Questionnaire to be filled by parents with detailed family history, developmental milestones (gross motor, fine motor, social, cognitive and language), history of physical problems (seizures, hearing/visual impairment, gait problems, weakness etc.

2. Clinical profile sheet - Family History: Type, Family size, 3 generation genogram; living arrangement; history of psychiatric illness in family(affective, non-affective, anxiety, tic, substance use, seizures, mental retardation, ADHD) Personal history (prenatal, perinatal, postnatal); Developmental history (milestones); Schooling History (normal/special/ not 


\section{Clinical Profile of Children with Intellectual Developmental Disorder Institution Based Cross Sectional Study}

going/ dropped out), school refusal; Sexual history; Temperament (easy, slow to warm up, difficult); Past history (trauma, head injury, infections, drug exposure) ; co-morbid medical diagnosis.

The following scales were administered by the investigator.

3. AAMD Adaptive Behaviour Scale- Revised (ABS-R) (Part II) (modified

4. Vineland Social Maturity Scale (VSMS)

5. International Clinical Epidemiological Network diagnostic tool for neuromotor impairments for primary physicians (INCLEN-NMI)

6. INCLEN Diagnostic tool for AUTISM SPECTRUM DISORDERS (INCLEN-ASD)

7. INCLEN Diagnostic tool for ADHD

\section{Procedure:}

\section{Step 1: Patient Recruitment Procedure}

Children were recruited for the study, from the special school, after being diagnosed to have Intellectual developmental Disorder (IDD) by principal investigator . Informed consent from the parent or guardian and assent where applicable, from the child were obtained before the child was recruited in to the study. Informed consent and assent was obtained in a language well understood by the parent/guardian and the child. Informed consent was also taken from the parents to interview the teacher.

\section{Step 2: Detailed History Collection}

The Socio-demographic details and the clinical profile of the child were assessed by the principal investigator.

\section{Step 3: Establishment of diagnosis and co morbidity}

The AAMD-Behavioural scale was administered to the child to establish the behavioural problems in these children. VSMS was administered to assess the social age of the child. INCLEN- ASD tool was administered if the child has co morbid pervasive developmental disorder clinically.

\section{Step 4: Assessment of ADHD}

If hyperactivity and inattentive symptoms were found in AAMD scale then INCLEN- ADHD tool was administered to assess whether they had the diagnostic criteria of ADHD and also whether it is only inattention, only hyperactivity/impulsiveness or combined type

\section{Step 5: Assessment of co morbid neuromotor impairment}

Assessment of neuromotor impairment was done using INCLEN NMI tool and assessed if they had cerebral palsy, upper or lower motor neuron disease findings.

\section{Step 6: Statistical analysis}

The data was tabulated and evaluated using the Statistical Package for Social Sciences (SPSS Version 17.0). Descriptive statistics were used for preliminary analysis. Mean and Standard deviation were used to describe continuous variables and proportions for categorical 


\section{Clinical Profile of Children with Intellectual Developmental Disorder Institution Based Cross Sectional Study}

variables. Chi-square test was used to check association between variables. Odds ratio, likelihood ratio and $95 \%$ confidence interval were calculated and a $\mathrm{P}$ value of $<0.05$ was taken as significant. There were 100 subjects from whom all baseline history and assessments were obtained including socio-demographic details, clinical variables, and scores from various rating scales.

\section{RESULTS}

This institution based cross sectional study was aimed to outline the clinical profile of children with intellectual developmental disorder and to study co morbid neuropsychiatric disorders in these children.

The mean age of the study population is 11.5 yrs with a standard deviation of 3.4. In the study population $42 \%$ were boys and $17 \%$ were girls belonging to the age group of $6-12$ yrs. Among children in the age group $13-18$ yrs, 26 were boys and 15 were girls.

Table 1 shows the socio demographic profile of the study population.

Table 2 describes the family history of mental illness

Table 3 depicts the history of certain relevant characteristics

Table 4 represents the co morbid medical conditions

Table 5 describes the Social Quotient classification

Most common medical co morbidity was seizures. There is no notable increase in the number of children with physical problems among those with history of Post natal distress or LBW. No notable increase of medical co morbidity in children with psychiatric morbidities.

According to VINELANDS SOCIAL MATURITY SCALE, 27\% of children had social maturity age level of 4 to 5 years. Corresponding social scores were taken and social quotients were calculated. Mean SQ was 48.79 with a SD of 16.89. Gender and Vineland Social Scales show a significant association. Chi- square value -16.689 (df - 7), p-value $-<0.02$.ie females were found to have statistically significant increase in social score values when compared to male children.

Clinical features (CF) of Down's syndrome were present in 19 percent in the population. Children with Downs have a lesser incidence of ADHD and Autism and the finding is statistically significant ( $p$ value 0.02.) Children with history of low birth weight (LBW) have higher odds of having CF of Down's syndrome when compared with children who do not have a history of low birth weight. Chi-square value -4.321 , p-value 0.038. OR -2.995(1.034, 8.673).

Table no.6 describes the characteristics of children with clinical features of Down's syndrome. Cerebral palsy was present in $12 \%$ of the sample. Significant association between family history and NMI scale noted. Chi- square value -58.14 (df - 9), p-value $-<0.001$. 


\section{Clinical Profile of Children with Intellectual Developmental Disorder Institution Based Cross Sectional Study}

Pervasive developmental disorder not otherwise specified was the most common autism spectrum disorder and it was present in $20 \%$ of the sample population. No association between other variables and INCLEN TOOL FOR ASD could be found.

ADHD was reported in $26 \%$ of the population. There is significant association between ADHD and increasing severity of intellectual disability according to the SQ. No association between other morbidities and increasing severity of intellectual disability. As behavioural problems are common in children with intellectual disability AAMD scale sub scores were used to identify behavioural problems in the sample. Odd behaviour was most common behavioural problem reported with $38 \%$ of sample population having it. Stereotyped behaviour was second common with $37 \%$ and followed by violent behaviour towards others (26\%). Antisocial behaviour was not reported in these children. Complaints regarding sleep was not described probably because the study is institution based. Disruptive behaviour was noted in $11 \%$ of the children. In those children with family history of IDD 30\% had disruptive behaviour and the finding was statistically significant. Self injurious behaviour reported in our study is in $18 \%$. There was statistical association between low birth weight and stereotyped behavior. Withdrawal behaviour was seen in $19 \%$. Rebellious behaviour in 19\%. Hyperactive behaviour in $25 \%$. Significant association between relevant family history and disruptive behavior seen. In those with a family history of MR, 30\% showed disruptive behavior. Chi- square value - 9.5 (df - 3), p-value - < 0.02. Significant association between history of LBW and stereotyped behavior was present. $32 \%$ have h/o LBW among those with stereotyped behavior. Chi- square value - 5.0 (df - 1), pvalue $-<0.02$. Significant association between lack of sense of danger and gender was present. Among those with somewhat abnormal lack of sense of danger, $58 \%$ are females. Chi- square value -6.7 (df - 1), p-value $-<0.009$. Significant association between lack of sense of danger and relevant family history found. Among those with lack of sense of danger, 52\% have a family history of either MR or psychiatric disease. Chi- square value - 13.3 (df - 3), p-value - < 0.004.Significant association between tendency for wandering off and relevant Family history. Among them with tendency for wandering off, $40 \%$ have a Family history of either MR or psychiatric disease. Chi- square value -12.4 (df - 3), p-value $-<0.006$.

Analysis of the age categories showed no significance although it was noted that the numbers are more in the lower age group for all behaviors except rebellious behavior and tendency to wander off.

\section{DISCUSSION}

$68 \%$ of sample population in this study were males and 32\%were females. 59\%of the sample population were in the age group between 6 to 12 years.41\% belonged to the adolescent group of 13 to 18years.out of $32 \%$ of females in total $15 \%$ were adolescent females. Mean age in the study was $11.5^{+}+3.4 . \mathrm{I} \mathrm{n}$ a study done by christoday ${ }^{9}$ et al in patients attending the child 


\section{Clinical Profile of Children with Intellectual Developmental Disorder Institution Based Cross Sectional Study}

psychiatric unit (CPU.) of the Central Institute of Psychiatry (C.I.P) over a one year period in 1998 showed $68.33 \%$ patients were males and $31.67 \%$ patients were females. And the mean age of the patients were 10.62 3 3.67.Across the globe the prevalence of intellectual developmental disorder is $1 \%$ and is seen that it is 1.5 times more in males. Our study also reports increased prevalence in males. In a study done by Jyothy prakash ${ }^{10}$ etal in 2007 among children. in the age group of 6 to 14 years $70 \%$ were in the age group of $6-11$ years. Bhatia ${ }^{11}$ etal in their study in 2014 in a general hospital psychiatric unit reported $43.4 \%$ of children in the age group of less than 12 years. This is a promising finding because children with intellectual disability as we know needs early intervention and training for maximum improvement and so increasing number trend in the child group in such special schools are really promising signs. Children from Hindu population belonged to 59\% of sample population, study by Jyothi prakash etal in 2007 also reported Religion wise distribution reflecting more of the children to be Hindus. Family history of IDD was reported in $20 \%$ and family history of psychiatric illness in $7 \%$. In a study by Amit nagarkar ${ }^{12}$ et al family history of MR was present evident in 3.3\%.this results points to the importance of assessing the family history and genetic vulnerability in children with IDD which in turn has implications in genetic counselling, early identification and prevention of neurodevelopmental disorders. Also we need further studies in this area with normal control group to check the statistical significance of such important findings.

In the present study developmental delay was reported in $96 \%$ of the population, study by Amit nagarkar et al reports $86.7 \%$ patients had a delay in achieving sensory milestones and $76.7 \%$ patients reported delay in achieving motor milestones. This finding is important because early identification of intellectually disabled children is possible by regular monitoring for growth and development in all spheres of gross motor, fine motor, social, cognitive and language areas. Low birth weight was reported in $47 \%$ of the sample population and post natal distress was reported in $40 \%$ of these children. Study by Vykuntaraju K. Gowda ${ }^{13}$ et al in 2015 observed in children with cerebral palsy and intellectual disability $30 \%$ had low birth weight and $43 \%$ of children had post natal asphyxia and complaints. We need comparison with controls for this important finding because while focusing on the preventive aspects we can work through adequate antenatal care, nutrition of mothers and improve perinatal quality of care. Mean social quotient observed in this study was $48.79+-16.9$. 39\% of the children belonged to mild IDD, 25\%belonged to moderate IDD and 21\% severe IDD. In the study done by Amit Nagarkar et al in a sample of 60 patients mean IQ observed was 53. Severity of retardation in patients was assessed using grades of intelligence and was found that More than half, i.e. 58\% of the patients had mild MR, while 30\% had moderate MR and severe retardation was evident in around $12 \%$ of the patients. This shows overall increased prevalence of mild IDD among the severity level of IDD. Among the medical co morbidities seizure disorder was most common with 31\% having seizures at least once in life time. Epilepsy was the commonest medical illness; seen in $61.90 \%$ of the patients in the study done by christoday et al in1998.Epilepsy had been reported to be common among the retarded, 


\section{Clinical Profile of Children with Intellectual Developmental Disorder Institution Based Cross Sectional Study}

especially the severely retarded in another study by Corbettetal ${ }^{14}, 1975$. An explanation for this could be the fact that patients with medical illness might have suffered from a cerebral damage which was responsible for the retardation. In a study by Ram lakan ${ }^{15}$ etal in 2013 demonstrated that lower IQ scores are correlated with epilepsy in children with ID. The study also reported that in Children with ID those had family history of mental illness, mental retardation and epilepsy showed higher chances of having epilepsy. Our study could not obtain significant association between seizure disorder and relevant family history, also no association between severity of IDD and seizure disorder could be elicited.

Down's syndrome clinical features were seen in 19 percent of the sample population. Down's syndrome is the most common chromosomal abnormality leading to IDD. Hence this finding has importance. It was also noted that psychiatric morbidities are less reported in this children and this finding is statistically significant. King ${ }^{16}$ etal reported commonly noted behavioural problems in children with Down's syndrome include attention difficulties, impulsivity, hyperactivity, occasional aggression. No significance could be observed with respect to sex, religion and age groups. Children with Down syndrome were found to have low birth weight and the finding was statistically significant. This finding was reported by Martin $\mathrm{BA}^{17}$ et al in their study. Cerebral palsy (CP) was reported in $12 \%$ of sample population. Vykuntaraja gowda et al in their study in 2015 reported after studying all children presenting with clinical features suggestive of $\mathrm{CP}$ to the neuro developmental clinic at Indira Gandhi Institute of Child Health over a period of 1-year (January 2012 to January 2013) reported that Intellectual sub- normality ( I Q <70) was observed in $55 \%$ of cases. Other co-morbidities observed by him were speech abnormalities in $38 \%$, visual problems in $26 \%$ ( strabismus, nystagmus, cataract, amblyopia, and cortical blindness), hearing impairment in $11 \%($ sensory neural hearing loss) Hence our study finding is important and we need further studies in this area with control group. There was significant association between family history of mental retardation and neuromotor impairment scale. Family history of cerebral palsy was considered in the study done by vykuntaraja et al in the sample population of cerebral palsy children. But considering the onset and clinical presentation of neurodevelopmental disorders and genetic susceptibility we need further researches in this area.

Pervasive developmental disorders were reported in $20 \%$ of sample population. We know that pervasive developmental disorders are a group of clinical syndromes that present as developmental delay and deviant behaviours. Leventa ${ }^{18}$ in their study in 1998 reported only20 to $30 \%$ of autistic children have IQ 70 or more. Hence our findings also are important and we need systematic assessment and intervention in these children with both autistic spectrum disorders and intellectual disability because they add to each other in terms of morbidity and quality of life of the child. 


\section{Clinical Profile of Children with Intellectual Developmental Disorder Institution Based Cross Sectional Study}

ADHD was reported in $26 \%$ of sample population. There was significant association between increasing severity of intellectual disability and ADHD. The prevalence of ADHD in children with mental retardation was found to be $8-19 \%$ in a study by santhosh ${ }^{19}$ pj et al in 1999.in the study by Jyothi prakash et al in 2007 it was observed that as severity of IDD increases the chances of behavioural problems increase.

Ram lakhan etal in their study on mentally retarded children reported Violent and destructive behaviour in 56.7\%. Temper tantrums 69.2\% Misbehaves with others $26.9 \%$ Self-injurious behaviour 25.9\% Repetitive behaviour 25.9\% Odd behaviour 32.7\% Hyperactivity 20.2\% Rebellious behaviour 15.4\%, Antisocial behaviour 15\%. Jyothi Prakash etal in their study in 2007 in mentally retarded children with CBCL scale reported that Common behaviour problems were impulsive or acts without thinking', 'cannot concentrate' \& 'sudden changes in mood or feelings'. This shows the importance of detailed assessment of behavioural problems in these children as we have done earlier for early identification and intervention of same.

\section{STRENGTHS AND LIMITATIONS}

This research will serve as an important contribution to the field of child behaviour and would encourage further research in this area. Also institution based studies are scarce in this area. Wide representation of sample population and good sample size makes our conclusions valid. However there are few limitations because there is no comparison group. Hence assessing the statistical significance of variables involved is not possible. Also the study design was cross sectional, several prospective studies will be required to confirm whether the study results can be generalised.

\section{CONCLUSION}

We do know that diagnosis and treatment of medical and behavioural problems in children with IDD is a long neglected aspect of practise of psychiatry. In fact we now know that these individuals experience same range of medical and psychological problems like others. The prevalence may be several times higher than that of people with no significant deficit in cognitive ability and adaptive function. A complete and competent evaluation of these children is the need of the hour.

When awareness regarding early detection and intervention improves we can hope to get better results. This study highlights the importance of eliciting family history and genetic vulnerability where by which we can improve detection and treatment. We need further studies in this area with control group so that we can incorporate genetic counselling and other preventive strategies. Defining and diagnosing psychiatric disorders in these children is a long standing challenge. An assessment based on intellectual age rather than chronological age is needed and the possibility of differing expressions of subjective emotional content in these children with limited repertoire 


\section{Clinical Profile of Children with Intellectual Developmental Disorder Institution Based Cross Sectional Study}

of such expressions must be considered. The presence of behavioural issues underscores the vital nature of psychiatric involvement as a multidisciplinary team in assessment and intervention of children with IDD.

\section{Acknowledgments}

The author appreciates all those who participated in the study and helped to facilitate the research process.

\section{Conflict of Interests}

The author declared no conflict of interests.

\section{REFERENCES}

1. World Health Organization, (2001), Mental Health Around the World, World Health Day.

2. American Psychiatric Association, (2013), Diagnostic and Statistical Manual of Mental Disorders, $5^{\text {th }}$ Edition. Washington, DC American Psychiatric Association.

3. ICMR .In: MadhavanT, Kalyan M, Naidu S et al. editors, (1983), Mental retardation: A manual for psychologists, National Institute for the Mentally Handicapped (under the ministry of social justice and empowerment, Government of India), Andhra Pradesh, India.

4. Shalini. In: MadhavanT, Kalyan M, Naidu S et al. editors, (1983), Mental retardation: A manual for psychologists. National Institute for the Mentally Handicapped (under the ministry of social justice and empowerment, Government of India), Andhra Pradesh, India.

5. Silka VR, Hauser MJ, (1997), Psychiatric assessment of the person with mental retardation. Psychiatric Annals ;27:162-169.

6. Hauser MJ, (1997), The role of a psychiatrist in mental retardation. Psychiatric Annals ;27:170-173.

7. Neece CL, Baker BL, Crinic KA, Blacher J, (2013), Examining the validity of ADHD as a diagnosis for adolescent with intellectual disability: Clinical presentation. Journal of Abnormal Child Psychology, 41(4):597 -612.

8. Singh TK, Indla V, Indla RR (2008), Impact of disability of mentally retarded on their parents. Indian Journal of Psychological Medicine, 30:98-104.

9. Christoday. R.J.Khess, Indran Idutta, Indrani chakrabarty, Piyali Bhattacharya, Jnanamay Das, Sonia Kothari ,(1998), Co morbidity in children with mental retardation. Indian Journal of Psychiatry,40(3),289-294

10. Jyoti Prakash, S. Sudarsanan, H.R.A. Prabhu,(2007), Study of Behavioural Problems in Mentally Retarded Children. Delhi Psychiatry Journal, 10:(1)

11. M.S. Bhatia, Shruti Srivastava, Priyanka Gautam, Jaswinder Kaur, (2014), Clinical profile and co-morbidity pattern in patients with intellectual disability. Delhi Psychiatry Journal, 17: (2) 


\section{Clinical Profile of Children with Intellectual Developmental Disorder Institution Based Cross Sectional Study}

12. Amit Nagarkar, Jagdish Prashad Sharma, S. K. Tandon, Pritesh Goutam, (2014), the clinical profile of mentally retarded children in India and prevalence of depression in mothers of the mentally retarded. Indian Journal of Psychiatry,56(2): 165-170.

13. Vykuntaraju K. Gowda, Anil Kumar, Sanjay K. Shivappa, Praveen Kumar Srikanteswara, Shivananda, M. S. Mahadeviah, M. Govindraj, and Premalatha, (2015), Clinical profile, predisposing factors and associated co morbidities of children with cerebral palsy in south India, Journal of Pediatric neurosciences,vol10,108-113.

14. Corbett J A, (1977) Epidemiological approaches in child psychiatry. London: Academic press.

15. Ram Lakhan ,2013, Intelligence quotient is associated with epilepsy in children with intellectual disability in India, Journal of Neurosciences in Rural Practice, Vol 4,408-412.

16. King BH, DeAntonio C, McCraken JT, et al,(1994) Psychiatric consultation in severe and profound mental retardation. American Journal of Psychiatry, $151: 1802-8$

17. Martin BA, (1997) Primary care of adults with mental retardation living in the community. American Family Physician,56,485-94.

18. Leventhal BL, Crotts ME, Cook EH. Austic disorder and other pervasive developmental disorders. In:Tasman A, kay J, Lieberman JA, editiors, (1997) Psychiatry Vol 1.Philadelphia:WB Saunders;,650-66.

19. Santhosh Pj, Baird G, (1999), Psychopharmacotherapy in children and adults with intellectual disability. Lancet 354:233-42.

\section{TABLES}

Table 1 : Socio demographic Characteristics of the Study Population

\begin{tabular}{|l|l|l|l|}
\hline \multicolumn{2}{|l|}{ Characteristic } & Frequency & Percentage \\
\hline \multirow{3}{*}{ Gender } & Female & 32 & 32 \\
\cline { 2 - 4 } & Male & 68 & 68 \\
\hline \multirow{2}{*}{ Age } & $6-12$ Yrs & 59 & 59 \\
\cline { 2 - 4 } & $13-18$ Yrs & 41 & 41 \\
\hline \multirow{2}{*}{ Religion } & Christian & 5 & 5 \\
\cline { 2 - 4 } & Hindu & 59 & 59 \\
\cline { 2 - 4 } & Muslim & 36 & 36 \\
\hline No family history of psychiatric illness & 72 & 72 \\
\hline No history of co - morbid medical conditions & 55 & 55 \\
\hline
\end{tabular}

Table No 2: Family History of Psychiatric Illness in the Sample

\begin{tabular}{|l|l|l|}
\hline Variables & Frequency & Percentage (\%) \\
\hline No Family History & 72 & 72 \\
\hline Family H/O Mr & 20 & 20 \\
\hline $\begin{array}{l}\text { Family H/O Mr \& Psychiatric } \\
\text { Problems }\end{array}$ & 1 & 1 \\
\hline
\end{tabular}

(C) The International Journal of Indian Psychology, ISSN 2348-5396 (e)| ISSN: 2349-3429 (p) | 94 
Clinical Profile of Children with Intellectual Developmental Disorder Institution Based Cross Sectional Study

\begin{tabular}{|l|l|l|}
\hline Variables & Frequency & Percentage (\%) \\
\hline Psychiatric Problems & 7 & 7 \\
\hline Total & 100 & 100 \\
\hline
\end{tabular}

Table No.3: History of Relevant Characteristics in the Sample

\begin{tabular}{|l|l|l|l|}
\hline Characteristic & & Frequency & Percentage (\%) \\
\hline History of post natal & Absent & 60 & 60 \\
\cline { 2 - 4 } distress & Present & 40 & 40 \\
\hline \multirow{2}{*}{$\begin{array}{l}\text { History of Low Birth } \\
\text { Weight }\end{array}$} & Absent & 53 & 53 \\
\hline History of & Present & 47 & 47 \\
\cline { 2 - 4 } Developmental Delay & Present & 4 & 4 \\
\hline
\end{tabular}

Table No.4: History Of Co Morbid Medical Conditions In Sample

\begin{tabular}{|l|l|l|}
\hline Variables & Frequency & Percentage (\%) \\
\hline Nil & 55 & 55 \\
\hline Seizures & 31 & 31 \\
\hline $\begin{array}{l}\text { Seizures, } \\
\text { Visual Impairment }\end{array}$ & 3 & 3 \\
\hline Seizure, Others & 3 & 3 \\
\hline Hearing Impairment & 1 & 1 \\
\hline $\begin{array}{l}\text { Hearing Impairment, Visual } \\
\text { Impairment }\end{array}$ & 1 & 1 \\
\hline Visual Impairment & 3 & 3 \\
\hline Visual Impairment, Others & 1 & 1 \\
\hline Others & 2 & 2 \\
\hline Total & 100 & 100 \\
\hline
\end{tabular}

Table No.5: Social Quotients Of Sample based On Severity Of Intellectual Disability

\begin{tabular}{|l|l|}
\hline $50-69$ (Mild IDD) & 39 \\
\hline $35-49$ (Mod IDD) & 25 \\
\hline $20-34$ (Severe IDD) & 21 \\
\hline$<20$ (Profound) & 1 \\
\hline
\end{tabular}




\section{Clinical Profile of Children with Intellectual Developmental Disorder Institution Based Cross Sectional Study}

Table no.6 Factors associated with Down's Syndrome

\begin{tabular}{|c|c|c|c|c|}
\hline Characteristic & & $\begin{array}{l}\text { Clinical } \\
\text { features of } \\
\text { Down's } \\
\text { syndrome } \\
\text { present[19] }\end{array}$ & $\begin{array}{l}\text { Clinical features } \\
\text { of Down's } \\
\text { syndrome } \\
\text { absent [81] }\end{array}$ & p-value \\
\hline \multirow[t]{2}{*}{ 1. Gender } & Female & 6 & 26 & \multirow[t]{2}{*}{0.965} \\
\hline & Male & 13 & 55 & \\
\hline \multirow[t]{2}{*}{ 2. Age groups } & $6-12$ yrs & 12 & 44 & \multirow[t]{2}{*}{0.485} \\
\hline & $13-18$ yrs & 7 & 37 & \\
\hline \multirow[t]{2}{*}{$\begin{array}{l}\text { 3. History of Low } \\
\text { Birth Weight }\end{array}$} & Absent & 6 & 47 & \multirow{2}{*}{$\begin{array}{ll}0.038 & \\
\text { OR } & 2.995 \\
(1.034,8.673)\end{array}$} \\
\hline & Present & 13 & 34 & \\
\hline \multirow[t]{3}{*}{ 4. Religion } & Christian & 2 & 3 & \multirow[t]{3}{*}{0.450} \\
\hline & Hindu & 10 & 49 & \\
\hline & Muslim & 7 & 29 & \\
\hline
\end{tabular}

Table no.7 Behavioural problems in the study population based on AAMD score

\begin{tabular}{|c|l|}
\hline Behavioural problems & Percentage (\%) \\
\hline 1. Odd behaviour & 38 \\
\hline 2. Stereotyped behaviour & $37 \%$ \\
\hline 3. Violent behaviour towards others & 26 \\
\hline 4. Self injurious behaviour & 18 \\
\hline 5. Disruptive behaviour & 11 \\
\hline 6. Hyperactive & 25 \\
\hline 7. Withdrawal & 19 \\
\hline 8. Rebellious & 19 \\
\hline
\end{tabular}

How to cite this article: Vidyadharan V, Joy T, Sukumaran P (2016), Clinical Profile of Children with Intellectual Developmental Disorder Institution Based Cross Sectional Study, International Journal of Indian Psychology, Volume 4, Issue 1, No. 81, ISSN:2348-5396 (e), ISSN:2349-3429 (p), DIP:18.01.129/20160401, ISBN:978-1-365-59365-9 